\title{
Evaluation on Pharmacological Activities of 2,4-Dihydroxybenzaldehyde
}

\author{
Hyun-Joo Jung ${ }^{1}$, Yun Seon Song ${ }^{2}$, Chang-Jin LIM" ${ }^{3, *}$, and Eun-Hee PARK ${ }^{2, *}$ \\ ${ }^{1}$ Brain Korea 21 Project for Medical Science, Department of Anatomy, Yonsei University College of Medicine, Seoul 120-752, \\ ${ }^{2}$ College of Pharmacy, Sookmyung Women's University, Seoul 150-742, ${ }^{3}$ Division of Life Sciences and Research Institute \\ of Life Sciences, Kangwon National University, Chuncheon 200-701, Republic of Korea
}

(Received May 12, 2009; Revised June 16, 2009; Accepted June 22, 2009)

\begin{abstract}
Hydroxybenzaldehyde, a phenolic compound found in a variety of natural sources, was previously shown to contain anti-inflammatory and related anti-angiogenic and anti-nociceptive activities. The present work was designed to assess some pharmacological activities of 2,4-dihydroxybenzaldehyde (DHD), an analogue of 4-hydroxybenzaldehyde. DHD exhibited a significant inhibition in the chick chorioallantoic membrane (CAM) angiogenesis, and its $\mathrm{IC}_{50}$ value was $2.4 \mu \mathrm{g} / \mathrm{egg}$. DHD also contained in vivo antiinflammatory activity using acetic acid-induced permeability and carrageenan-induced air pouch models in mice. In the air pouch model, DHD showed significant suppression in exudate volume, number of polymorphonuclear leukocytes and nitrite content. DHD showed an anti-nociceptive activity in the acetic acid-induced writhing test in mice. It also suppressed enhanced production of nitric oxide (NO) and elevated expression of inducible nitric oxide synthase (iNOS) and cyclooxygenase-2 (COX-2) in lipopolysaccharide (LPS)-stimulated RAW264.7 macrophage cells. It was able to slightly decrease the level of reactive oxygen species in the stimulated macrophages. DHD at the used concentrations couldn't modulate the viabilities of RAW264.7 cells. Taken together, like 4-hydroxybenzaldehyde, DHD contains anti-angiogenic, anti-inflammatory and anti-nociceptive activities.
\end{abstract}

Keywords: Anti-angiogenic, Anti-inflammatory, Anti-nociceptive, Cyclooxygenase-2, 2,4-dihydroxybenzaldehyde, Inducible nitric oxide synthase, Nitric oxide, RAW264.7, Reactive oxygen species

\section{INTRODUCTION}

2,4-Dihydroxybenzaldehyde (DHD, $\beta$-resorcylaldehyde, Fig. 1) is one of the phenolic components identified in various natural products, including Cassia grandis (González et al., 1996) and acacia wood (de Simón et al., 2009). It can also be synthesized and used to be a starting material for organic synthesis of a variety of useful substances (Pattekhan and Divakar, 2001; Yang and Meng, 2008). DHD was shown to contain antibacterial activity against the four pathogenic bacteria, such as Campylobacter jejuni, Escherichia coli, Listeria monocytogenes, and Salmonella enterica (Friedman et al., 2003). Its phosphate exhibited slow-binding inhibition on fructose bisphosphate aldolase, which involved active-site Schiff-base formation

\section{${ }^{*}$ Corresponding authors}

Tel: +82-2-710-9565 Fax: +82-2-3273-5847

E-mail: ehpark@sookmyung.ac.kr

Tel: +82-33-250-8514 Fax: +82-33-242-0459

E-mail: cjlim@kangwon.ac.kr and required a phenol group ortho to the aldehyde moiety (Blonski et al., 1997). DHD showed weak scavenging activities towards peroxynitrite and hydroxy radicals, potent oxidants that have a potentially causative effect on cancer and other deleterious pathogenesis of various diseases<smiles>O=Cc1ccc(O)cc1O</smiles>

2,4-Dihydroxybenzaldehyde (DHD).

Fig. 1. Chemical Structure of 2,4-dihydroxybenzaldehyde (DHD), a phenolic component of plant origin. 
(Yang et al., 2001). Until recently, other biological activities of DHD have not been identified. 4-Hydroxybenzaldehyde, a DHD analogue and a major constituent of Gastrodia elata Blume, was shown to contain anti-angiogenic, anti-inflammatory and anti-nociceptive activities via down-regulating inducible nitric oxide synthase and cyclooxygenase-2 (Lim et al., 2008a). In this following work, it is demonstrated that DHD also possesses considerable anti-angiogenic, anti-inflammatory and anti-nociceptive activities in in vivo and in vitro experimental models.

\section{MATERIALS AND METHODS}

\section{Chemicals, fertilized eggs and experimental animals}

2,4-Dihydroxybenzaldehyde (DHD), 3,4-dihydroxybenzaldehyde, 2,4,6-trihydroxybenzaldehyde, 3-bromo-4-hydroxybenzaldehyde, 3,5-di-tert-butyl-4-hydroxybenzaldehyde, Evans blue, E. coli lipopolysaccharide (LPS), indomethacin and dexamethasone were obtained from Sigma Chemical Co. (St. Louis, MI, USA). 2',7'-Dichlorodihydrofluorescein diacetate (DCFH-DA) was from Invitrogen (Carlsbad, CA, USA). All other chemicals used were of reagent grade or better. Fertilized brown Leghorn eggs were purchased from Pulmuone Food Co., Seoul, Korea. Male ICR mice (male, 4-week-old, about $25 \mathrm{~g}$ ) were obtained from Samtaco Animal Farm, Osan, Korea, and acclimated for one week prior to treatment. The animal room was maintained at $23 \pm 2^{\circ} \mathrm{C}$ with a $12 \mathrm{~h} \mathrm{light/dark} \mathrm{cycle.} \mathrm{Food}$ and tap water were supplied ad libitum. The ethical guidelines, described in the NIH Guide for Care and Use of Laboratory Animals, were followed throughout the experiments.

\section{Cell culture}

The RAW264.7 cells, a murine macrophage cell line, were from American Type Culture Collection (Manassas, VA, USA). The macrophage cells were cultured in Dulbecco's modified Eagle's medium containing 10\% heat-inactivated fetal bovine serum (FBS), $25 \mathrm{mM}$ HEPES ( $\mathrm{pH}$ 7.5), $100 \mathrm{U} / \mathrm{ml}$ penicillin and $100 \mu \mathrm{g} / \mathrm{ml}$ streptomycin. The mammalian cells were maintained in a humidified atmosphere containing $5 \% \mathrm{CO}_{2}$, plated at a density of $1 \times 10^{6}$ and preincubated for $24 \mathrm{~h}$ at $37^{\circ} \mathrm{C}$. For all experiments, the macrophage cells were grown to $80-90 \%$ confluence, and subjected to no more than 20 cell passages.

\section{Chorioallantoic membrane (CAM) assay}

Anti-angiogenic activity of DHD was determined using CAM assay (Song et al., 2003) as follows. The fertilized eggs were kept at $37^{\circ} \mathrm{C}$ in a humidified egg incubator. After 3.5-day incubation, about $2 \mathrm{ml}$ of albumen was aspirated from the eggs through the small hole drilled at the narrow end, permitting the small CAM and yolk sac to drop away from the shell membrane. The shell covering the air sac was punched out and removed by forceps, and the shell membrane on the floor of the air sac was peeled away. In the 4.5-day-old chick embryo, a DHD-loaded Thermanox coverslip was applied onto the CAM surface. Two days after returning the chick embryo to the incubator, an appropriate volume of $10 \%$ fat emulsion (Intralipose, $10 \%$ ) was injected into a 6.5-day-old embryo chorioallantois. Using a score system under a microscope, the branching pattern of each egg was graded as $0,1+$ or $2+$. Convergence of a few vessels toward the CAM surface was denoted as $1+$, and $2+$ reflected an increased density and length of vessels toward the CAM surface.

\section{Acetic acid-induced vascular permeability test}

According to a modification of the method of Whittle (1964), acetic acid-induced vascular permeability test was used to assess anti-inflammatory activity of DHD. One hour after oral administration of DHD (10,30 or $100 \mathrm{mg} / \mathrm{kg})$ or indomethacin (IND, $10 \mathrm{mg} / \mathrm{kg}$ ), $0.1 \mathrm{ml} / 10 \mathrm{~g}$ body weight of $2 \%$ Evans blue solution was injected intravenously in each mouse. Ten min later, $0.1 \mathrm{ml} / 10 \mathrm{~g}$ body weight of $0.7 \%$ acetic acid in saline was intraperitoneally injected. Twenty min after the administration of acetic acid, the mice were sacrificed by cervical dislocation. After $10 \mathrm{ml}$ of saline was injected into the peritoneal cavity, the washing solutions were collected in test tubes. The concentration of Evans blue in the washing solution was spectrophometrically determined by the absorbance at $590 \mathrm{~nm}$. The vascular permeability was represented in terms of the absorbance $\left(A_{590}\right)$ which leaked into the peritoneal cavity.

\section{Carrageenan-induced air pouch formation}

According to a modification of the procedure of Ghosh et al. (2000), $\lambda$-carrageenan-induced air pouch formation was performed. Six days prior to the drug treatment, the air pouch was formed in the intrascapular region of rats by initial subcutaneous injection of $4 \mathrm{ml}$ sterile air and successive injections of $2 \mathrm{ml}$ sterile air every 3 days to sustain its patency (Sedgwick and Lees, 1986). On day 0, vehicle ( $2 \%$ Tween 80 in saline), DHD $(0.03,0.1$ and $0.3 \mathrm{mg} /$ pouch) or dexamethasone (DEXA, $0.01 \mathrm{mg} /$ pouch) was administered into the pouch just prior to the $\lambda$-carrageenan injection ( $0.1 \mathrm{ml}$ of $1.0 \%$ solution). After 16 hour, the pouch cavity was opened and the exudates were collected. The exudate volumes were measured using a graduate tube. Aliquots were diluted with Turk solution, and the poly- 
morphonuclear leukocytes were counted in a standard hemocytometer chamber. Experiments were performed in triplicate.

\section{Acetic acid-induced writhing response}

An anti-nociceptive activity of DHD was assessed as previously described (Olajide et al., 2000). The response to an intraperitoneal injection of acetic acid solution into mice, manifesting as a contraction of the abdominal muscles and stretching of hind limbs, was evaluated. Nociception was induced by intraperitoneal injection of $0.7 \%$ acetic acid solution at the dose of $0.1 \mathrm{ml} / 10 \mathrm{~g}$ body weight. Each experimental group was orally treated with vehicle $(1 \%$ CMC in saline), DHD $(10,30$ or $100 \mathrm{mg} / \mathrm{kg})$ or indomethacin (IND, $10 \mathrm{mg} / \mathrm{kg}$ ) as a positive control. From $10 \mathrm{~min}$ later, the number of writhes during the following $10 \mathrm{~min}$ was counted.

\section{Nitrite analysis}

Accumulated nitrite $\left(\mathrm{NO}_{2}{ }^{-}\right)$in the culture media or the exudates obtained from air-pouch experiment was determined according to a colorimetric assay based on the Griess reaction (Sherman et al., 1993; Kim et al., 2009). The samples $(100 \mu \mathrm{l})$, obtained after centrifugation, were mixed with $100 \mu \mathrm{l}$ Griess reagent $(6 \mathrm{mg} / \mathrm{ml})$ at room temperature for $10 \mathrm{~min}$, and then $\mathrm{NO}_{2}{ }^{-}$concentration was determined by the absorbance at $570 \mathrm{~nm}$. The calibration curve was constructed using the known concentrations of sodium nitrite.

\section{Determination of intracellular ROS}

For determination of intracellular ROS level, the redox-sensitive fluorescent probe DCFH-DA was used as previously described (Royall and Ischiropoulos, 1993). After preincubation with $\mathrm{DHD}(0,0.02,0.05 \mathrm{mM})$ for $1 \mathrm{~h}$, the RAW264.7 cells were treated with LPS for $24 \mathrm{~h}$. Afterwards they were incubated with $5 \mu \mathrm{M}$ DCFH-DA for $30 \mathrm{~min}$ at $37^{\circ} \mathrm{C}$. The harvested cells were immediately analyzed by a flow cytometry.

\section{Western analysis}

The RAW264.7 macrophage cells were treated with LPS $(1 \mu \mathrm{g} / \mathrm{ml})$ in the presence or absence of DHD for $24 \mathrm{~h}$ and then washed twice with ice-cold phosphate-buffered saline (PBS). The mammalian cells were lysed in a buffer containing $20 \mathrm{mM}$ HEPES (pH 7.9), $0.1 \mathrm{M} \mathrm{KCl}, 0.3 \mathrm{M} \mathrm{NaCl}$, $10 \mathrm{mM}$ EDTA, 1\% SDS, $1 \mathrm{mM}$ PMSF, $1 \mu \mathrm{g} / \mathrm{ml}$ leupeptin and $1 \mu \mathrm{g} / \mathrm{ml}$ pepstatin. For immunoblotting, anti-inducible nitric oxide synthase (anti-iNOS; Transduction Laboratories, Lexington, KY, USA), anti-cyclooxygenase-2 (anti-
COX-2; Transduction Laboratories, Lexington, KY, USA) and anti- $\beta$-actin (Sigma-Aldrich, St. Louis, MO, USA) antibodies were used.

\section{MTT reduction assay}

The cellular viability was quantified by the 3-(4,5- dimethylthiazol-2-yl)-2,5-diphenyltetrazolium bromide (MTT) assay (Freshney, 1994). Briefly, cells incubated with various concentrations of DHD were treated with $5 \mu \mathrm{l}$ of MTT (Sigma-Aldrich Co., St. Louis, MI, USA) solution $(5 \mathrm{mg} / \mathrm{ml}$ ) for $2 \mathrm{~h}$. The cells were then lysed with isopropyl alcohol, and the absorbance was read at the wavelength of 540 $\mathrm{nm}$.

\section{Statistical analysis}

The results were expressed as mean \pm S.E. Comparison between experimental groups was performed by ANOVA followed by the Tukey's multiple range tests. $p$ values less than 0.05 were considered to be significant.

\section{RESULTS AND DISCUSSION}

Down-regulation of angiogenesis prevents neoplastic growth and inflammation. Some anti-angiogenic components are effective in animal models of inflammation models, while several anti-inflamatory drugs, such as indomethacin, methotrexate and corticosteroids, contain anti-angiogenic activities (Tong et al., 2004). The CAM assay is in vivo used to measure both angiogenesis and anti-angiogenesis. Since 4-hydroxybenzaldehyde was previously found to contain an anti-angiogenic activity (Lim et al., 2008a), anti-angiogenic activities of its five analogues, such as 2,4-dihydroxybenzaldehyde (DHD), 3,4-dihydroxybenzaldehyde, 2,4,6-trihydroxybenzaldehyde, 3-bromo4-hydroxybenzaldehyde, 3,5-di-tert-butyl-4-hydroxybenzaldehyde, were preliminarily examined using the CAM assay (Table I). As shown in Table I, DHD appeared to be most

Table I. Comparison of anti-angiogenic activities of 4-hydroxybenzaldehyde analogues

\begin{tabular}{lc}
\hline \multicolumn{1}{c}{ 4-Hydroxybenzaldehyde } \\
analogues & $\mathrm{IC}_{50}(\mu \mathrm{g} / \mathrm{egg})$ \\
\hline 2,4-Dihydroxybenzaldehyde & 2.4 \\
3,4-Dihydroxybenzaldehyde & 13.9 \\
2,4,6-Trihydroxybenzaldehyde & 7.2 \\
3-Bromo-4-hydroxybenzaldehyde & $>50$ \\
3,5-Di-tert-butyl-4-hydroxybenzaldehyde & 30.6 \\
\hline
\end{tabular}

Anti-angiogenic activities of five 4-hydroxybenzaldehyde analogues were determined using chick chorioallantoic membrane (CAM) assay. 
effective among them. Accordingly, its anti-angigenesisrelated activities were elucidated.

After the 2-day treatment, retinoic acid, used as a positive control, at $1 \mu \mathrm{g} / \mathrm{egg}$ exhibited an inhibition of $89.5 \%$ in the branching patterns of blood vessels (Fig. 2). When 0.1, 0.3 and $3.0 \mu \mathrm{g} / \mathrm{egg}$ of DHD was applied onto the CAMs, the inhibition percentages in the CAM angiogenesis were $35.3 \%, 42.9 \%$ and $60.0 \%$, respectively (Fig. 2). This clearly indicates that DHD contains an anti-angiogenic activity in a dose-dependent manner. The $\mathrm{IC}_{50}$ value of $\mathrm{DHD}$ was $2.4 \mu \mathrm{g} / \mathrm{egg}$. Taken together, DHD contains an anti-angiogenic activity.

Though an anti-inflammatory activity of DHD has not been suggested so far, its in vivo anti-inflammatory activity has been assessed using the two in vivo models, vascular permeability and air pouch models. In a vascular permeability test as a typical model of the first stage inflammatory reactions, inflammatory mediators, released following sti-

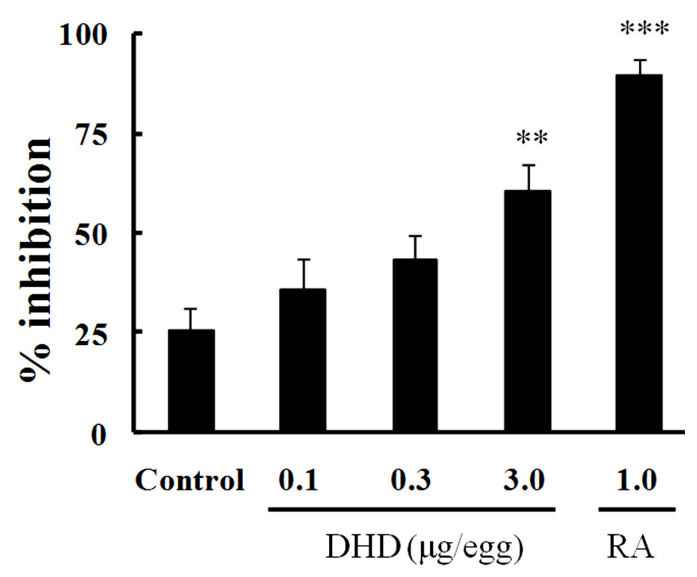

Fig. 2. Dose-dependent anti-angiogenic activity of 2,4-dihydroxybenzaldehyde (DHD) in the chick embryo chorioallantoic membrane (CAM) assay. Retinoic acid (RA, $1 \mu \mathrm{g} / \mathrm{egg}$ ) was used as a positive control. Each group contained at least 20 eggs. Each column represents mean $\pm \mathrm{S}$.E. of the three independent experiments. ${ }^{* *} p<0.01,{ }^{* * *} p<0.001$. Compared with the control group. mulation, lead to dilation of blood vessels and result in enhanced vascular permeability (Vogel and Vogel, 1997). DHD at the oral doses of 10,30 and $100 \mathrm{mg} / \mathrm{kg}$ showed an inhibition of $16.7 \%, 27.9 \%$ and $45.2 \%$ on vascular permeability, respectively (Table II). An inhibitory effect of DHD at $100 \mathrm{mg} / \mathrm{kg}$ is comparable to that of indomethacin (10 $\mathrm{mg} / \mathrm{kg}$ ) used as a positive control (Table II). In the carrageenan-induced air pouch model, an excellent model of acute inflammation, fluid extravasation, leukocyte migration and biochemical parameters in the exudate can be easily detected. Injection of carrageenan into an air pouch on the dorsal surface of mice triggers an inflammatory process. In the carrageenan-induced air pouches, dexamethasone (DEXA, $0.01 \mathrm{mg} / \mathrm{pouch}$ ), a nonselective cyclooxygenase inhibitor, reduced the exudate volume by $66.4 \%$ (Table III). Treatment with DHD at 0.03, 0.1 and 0.3 $\mathrm{mg} /$ pouch displayed an inhibition of $47.2 \%, 68.9 \%$ and $85.9 \%$, respectively, as compared to the control exudate volume (Table III). Total numbers of the polymorphonuclear leukocytes in the air pouches were also decreased by DHD at $0.03,0.1$ and $0.3 \mathrm{mg} /$ pouch, the inhibitory percentages of which were $26.3 \%, 58.6 \%$ and $73.8 \%$, respectively (Table III). DHD contains an acute anti-inflammatory

Table II. Inhibitory effects of DHD in acetic acid-induced vascular permeability and writhing response in mice

\begin{tabular}{lccc}
\hline Materials & $\begin{array}{c}\text { Dose } \\
(\mathrm{mg} / \mathrm{kg})\end{array}$ & \multicolumn{1}{c}{$\mathrm{A}_{590}$} & Number of writhings \\
\hline Control & - & $1.06 \pm 0.18$ & $26.2 \pm 1.30$ \\
DHD10 & 10 & $0.88 \pm 0.11(16.7)$ & $13.50 \pm 0.99(48.4)$ \\
DHD30 & 30 & $0.76 \pm 0.09^{\mathrm{b}}(27.9)$ & $9.33 \pm 0.71^{\mathrm{a}}(64.3)$ \\
DHD100 & 100 & $0.58 \pm 0.07^{\mathrm{b}}(45.2)$ & $3.50 \pm 0.67^{\mathrm{a}}(86.6)$ \\
IND & 10 & $0.65 \pm 0.09^{\mathrm{b}}(39.0)$ & $4.50 \pm 0.85^{\mathrm{b}}(82.8)$ \\
\hline
\end{tabular}

Indomethacin (IND, $10 \mathrm{mg} / \mathrm{kg}$ body weight) was used as a positive control. DHD (10, 30 and $100 \mathrm{mg} / \mathrm{kg}$ body weight) was orally administered. Vascular permeability was represented by the absorbance at $590 \mathrm{~nm}$. The results are expressed as mean \pm S.E. Each group contained 8 mice. This experiment was performed in triplicate. Figures in parentheses indicate inhibitory percentage with respect to the control group treated only with $1 \% \mathrm{CMC}$ in saline. ${ }^{a} p<0.05,{ }^{b} p<0.01$, compared with the control group.

Table III. Inhibitory effects of DHD on carrageenan-induced inflammation in the air pouch model

\begin{tabular}{ccccc}
\hline Group & Dose $(\mathrm{mg} /$ pouch $)$ & Exudate $(\mathrm{ml})$ & Total leukocytes $\left(\times 10^{7}\right.$ cells $)$ & Nitrite content $(\mu \mathrm{M})$ \\
\hline Control & - & $2.12 \pm 0.06$ & $4.51 \pm 0.32$ & $6.24 \pm 0.62$ \\
DHD0.03 & 0.03 & $1.12 \pm 0.11^{\mathrm{b}}(47.2)$ & $3.32 \pm 0.09^{\mathrm{b}}(26.3)$ & $5.82 \pm 0.43(6.7)$ \\
DHD0.1 & 0.1 & $0.66 \pm 0.12^{\mathrm{b}}(68.9)$ & $1.87 \pm 0.24^{\mathrm{b}}(58.6)$ & $4.88 \pm 0.39(21.7)$ \\
DHD0.3 & 0.3 & $0.30 \pm 0.06^{\mathrm{b}}(85.9)$ & $1.18 \pm 0.08^{\mathrm{b}}(73.8)$ & $2.59 \pm 0.27^{\mathrm{a}}(58.4)$ \\
DEXA & 0.01 & $0.72 \pm 0.07^{\mathrm{b}}(66.04)$ & $1.45 \pm 0.04^{\mathrm{b}}(67.7)$ & $2.30 \pm 0.19^{\mathrm{b}}(63.1)$ \\
\hline
\end{tabular}

The results are expressed as mean \pm S.E. of $n=8$. Figures in parentheses indicate inhibitory percentages with respect to the corresponding control group. Dose was expressed in $\mathrm{mg} /$ pouch. Dexamethasone (DEXA, $0.01 \mathrm{mg} /$ pouch) was used as a positive control. The control group was treated only with $2 \%$ Tween 80 in saline. This experiment was repeated in triplicate. ${ }^{a} p<0.05 ;{ }^{b} p<0.01$, compared with the control group. 
activity. In brief, it is assumed that an acute inflammatory activity of DHD results from its prevention on the release of inflammatory mediators at the first stage.

In the acetic acid-induced writhing response, an inhibitory mechanism of abdominal writhing induced by acetic acid involves the release of arachidonic acid metabolites via cyclooxygenase, and prostaglandin biosynthesis (Franzotti et al., 2002). As shown in Table II, DHD at 10, 30 and $100 \mathrm{mg} / \mathrm{kg}$, p.o., exhibited an inhibition by $48.4 \%$, $64.3 \%$ and $86.6 \%$, respectively, on the writhing response induced by acetic acid. Collectively, DHD contains an anti-nociceptive activity in addition to an anti-inflammatory activity, suggesting that prostaglandin biosynthesis might be commonly involved in the pharmacological activities of DHD.

Nitric oxide (NO), an important proinflammatory mediator in the pathogenesis of inflammatory process, is produced from $\mathrm{L}$-arginine by the three isoforms of nitric oxide synthase (NOS), such as neuronal NOS (nNOS), endothelial NOS (eNOS) and inducible NOS (iNOS). For expression of iNOS, the mammalian cells should be experimentally triggered by specific stimulants, including pro-inflammatory cytokines and bacterial LPS (Chesrown et al., 1994). Since iNOS-derived NO plays an important role in a variety of pathological conditions, such as inflammation and autoimmune diseases, and gives rise to cellular injury, suppression of iNOS is closely linked with anti-inflammatory action (Singh et al., 2000). Inhibitory effects of DHD was examined on LPS-induced NO production in the

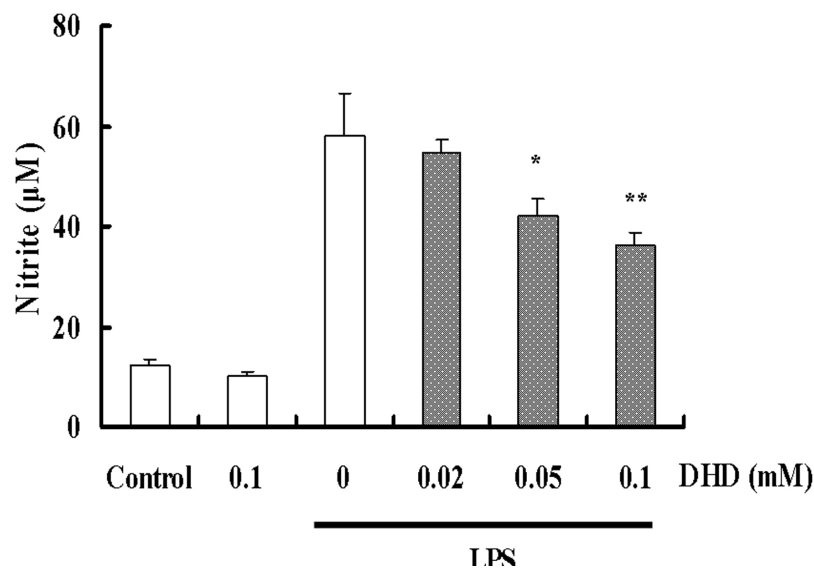

Fig. 3. Inhibitory effect of 2,4-dihydroxybenzaldehyde (DHD) on LPS-induced NO production in RAW264.7 macrophage cells. The mammalian cells were incubated for $24 \mathrm{~h}$ with LPS $(1 \mu \mathrm{g} /$ $\mathrm{ml}$ ) in the presence or absence of indicated concentrations of DHD. Accumulated nitrite in the culture medium was determined by the Griess reaction. The values are mean \pm S.E. of the three independent experiments. ${ }^{*} p<0.05,{ }^{* *} p<0.01$, compared with the LPS only.
RAW264.7 macrophages (Fig. 5). Level of the accumulated nitrite, determined by the Griess method, in the culture supernatants was used as an index for NO. After treatment with LPS, nitrite level markedly increased. When the RAW264.7 macrophage cells were treated with 0.02, 0.05 and $0.1 \mathrm{mM}$ DHD, NO production induced by LPS was suppressed in a dose-dependent manner (Fig. 3). The in vitro suppression by DHD in the induction of NO was supported by the result obtained with the air pouch model. As shown Table III, DHD was able to significantly decrease the nitrite content in the air pouches in a dose-dependent manner. With the assumption that suppression by DHD of NO induction might be caused by a decrease in the iNOS level, the effect of DHD on the iNOS expression was examined in the RAW264.7 macrophages cells activated with LPS. As shown in Fig. 4, DHD dose-dependently suppressed iNOS induction without changes in the levels of $\beta$ actin, an internal control. This result suggests that DHD specifically inhibits iNOS induction in the LPS-stimulated macrophage cells. Non-steroidal anti-inflammatory drugs (NSAIDs), known to be very beneficial in the treatment of various inflammatory disorders, target cyclooxygenase (COX), a rate-limiting enzyme involved in the conversion of arachidonic acid into inflammatory prostaglandins. In contrast to constitutive expression of cyclooxygenase-1 (COX-1), cyclooxygenase-2 (COX-2) is induced by tissue damage during inflammatory process. Various natural products of plant origin contain anti-inflammatory activities via suppression of COX-2 (Jachak, 2006). DHD was able to suppress COX-2 induction in LPS-stimulated RAW264.7 macrophage cells (Fig. 4). Although vanillin, an analogue

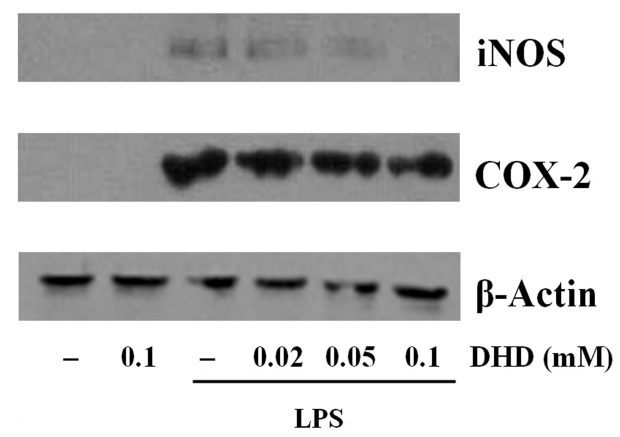

Fig. 4. Inhibitory effects of 2,4-dihydroxybenzaldehyde (DHD) on LPS-induced expression of iNOS and COX-2 in RAW264.7 macrophage cells. The mammalian cells were incubated for 24 $\mathrm{h}$ with LPS $(1 \mu \mathrm{g} / \mathrm{ml})$ in the presence or absence of indicated concentrations of DHD. After $24 \mathrm{~h}$ incubation, the cell lysates (30 $\mu \mathrm{g}$ protein) were separated by SDS-PAGE, transferred to a polyvinylidene difluoride membrane and blotted with appropriate antibodies. $\beta$-Actin was used an internal control. This blot is a representative of the three independent experiments. 


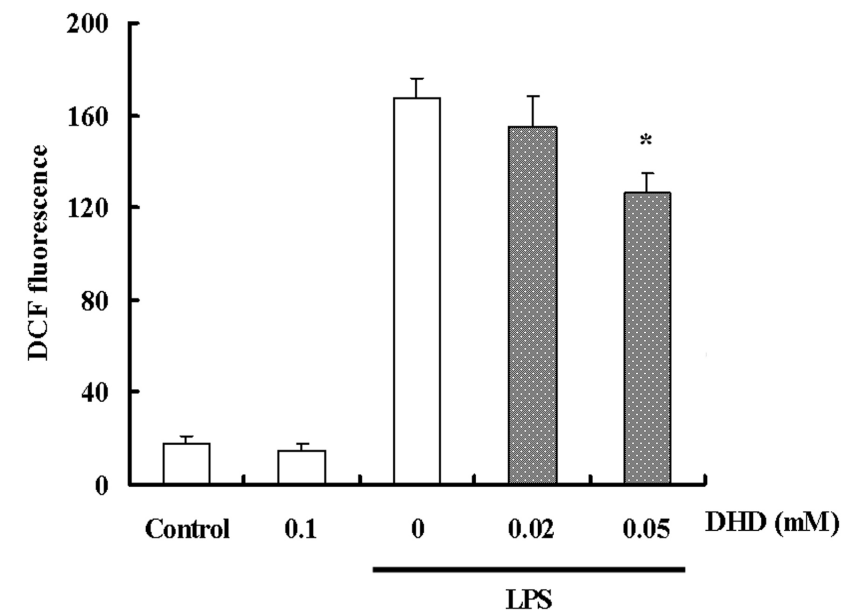

Fig. 5. Reduction of reactive oxygen species (ROS) level by 2,4-dihydroxybenzaldehyde (DHD) in RAW264.7 macrophage cells activated with LPS. The mammalian cells were incubated for $24 \mathrm{~h}$ with LPS $(1 \mu \mathrm{g} / \mathrm{ml})$ in the presence or absence of indicated concentrations of DHD. After $24 \mathrm{~h}$ incubation, the intracellular ROS levels were determined. ROS level was represented as DCF fluorescence. The values are mean \pm S.E. of the three independent experiments. ${ }^{*} p<0.05$, compared with the LPS only.

of DHD, contains anti-angiogenic, anti-inflammatory and anti-nociceptive activities, it was unable to suppress COX-2 induction in the LPS-activated macrophages (Lim et al., 2008b). However, vanillin suppressed NO production and iNOS induction in the LPS-activated macrophages (Lim et al., 2008b). Taken together, DHD is estimated to exhibit its anti-inflammatory and anti-nociceptive activities via the suppression of iNOS and COX-2 induction.

Although ROS at low concentrations act as important intracellular messengers of various physiological events, including cell proliferation and apoptosis, the increased production of ROS is cytotoxic and related with various diseases. As shown in Fig. 5, DHD was able to reduce ROS level in the macrophages, which was elevated by LPS. Previously, 4-hydroxybenzyl alcohol was identified to reduce the ROS level in the LPS-activated macrophages (Lim et al., 2007). No cytotoxic effects of DHD on the RAW264.7 macrophages were observed at the used concentrations, which was determined by the MTT assay (Fig. $6)$. DHD at $0.02,0.05$ and $0.1 \mathrm{mM}$ showed cellular survival similar to that of the untreated control (Fig. 6)

In conclusion, it has been clearly demonstrated that DHD possesses some novel pharmacological activities, such as anti-inflammatory, anti-angiogenic and anti-nociceptive activities via suppression of iNOS and COX-2 induction. This is the first finding on the pharmacological

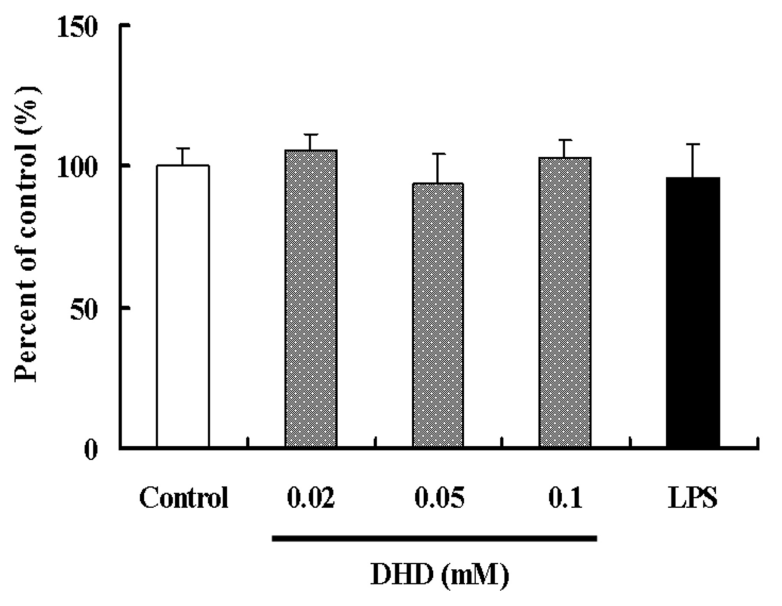

Fig. 6. Effect of 2,4-dihydroxybenzaldehyde (DHD) on the viability of RAW264.7 macrophage cells. Cell viability was measured by the MTT assay. The mammalian cells were treated with indicated concentrations of DHD or $1 \mu \mathrm{g} / \mathrm{ml}$ LPS for $24 \mathrm{~h}$. Data indicate mean \pm S.E. from three independent experiments.

activities of DHD.

\section{ACKNOWLEDGMENTS}

The authors especially thanks to Ms Hyun-Jung Kang for her technical assistance.

\section{REFERENCES}

Blonski, C., De Moissac, D., Périé, J. and Sygusch, J. (1997). Inhibition of rabbit muscle aldolase by phosphoylated aromatic compounds. Biochem. J. 323, 71-77.

Chesrown, S. E., Monnier, J., Visner, G. and Nick, H. S. (1994). Regulation of inducible nitric oxide synthase mRNA levels by LPS, INF-gamma, TGF-beta, and IL-10 in murine macrophage cell lines and rat peritoneal macrophages. Biochem. Biophys. Res. Commun. 200, 126-134.

De Simón, B. F., Esteruelas, E., Muñoz, A. M., Cadahía, E. and Sanz, M. (2009). Volatile compounds in acacia, chestnut, ash, and oak woods, with a view to their use in cooperage. $J$. Agric. Food Chem. 57, 3217-3227.

Franzotti, E. M., Santos, C. V. F., Rodrigues, H. M. S. L., Mourao, R. H. V. and Andrade, M. R. (2002). Anti-inflammatory, analgesic and acute toxicity of Sida cardiafolia $\mathrm{L}$. J. Ethnopharmacol. 72, 59-65.

Freshney, R. I. (1994). Culture of animal cells: a manual of basic technique. 4th ed., pp. 336-338, Wiley-Liss Press, New York.

Friedman, M., Henika, P. R. and Mandrell, R. E. (2003). Antibacterial activities of phenolic benzaldehydes and benzoic acids against Campylobacter jejuni, Escherichia coli, Listeria monocytogenes, and Salmonella enterica. J. Food Prot. 66, 1811-1821.

Ghosh, A. K., Hirasawa, N., Niki, H. and Ohuchi, K. (2000). Cyclooxygenase-2-mediated angiogenesis in carrageenaninduced granulation tissue in rats. J. Pharmacol. Exp. Ther. 
295, 802-809.

González, A. G., Bermejo, J. and Valencia, E. (1996). A new C6-C3 compound from Cassia grandis. Planta Med. 62, 176-177.

Jachak, S. M. (2006). Cyclooxygenase inhibitory natural products: current status. Curr. Med. Chem. 13, 659-678.

Kim, B. H., Lee, Y. G., Kim, T. W. and Cho, J. Y. (2009). Structural features of polyphenolic compounds in their NO inhibitory activities. Biomol. Ther. 17, 79-85.

Lim, E. J., Kang, H. J., Jung, H. J. and Park, E. H. (2007) Anti-angiogenic, anti-inflammatory and anti-nociceptive activity of 4-hydroxybenzyl alcohol. J. Pharm. Pharmacol. 59, 1235-1240.

Lim, E. J., Kang, H. J., Jung, H. J., Kim, K., Lim, C. J. and Park, E. H. (2008a). Anti-inflammatory and anti-nociceptive activities of 4-hydroxybenzaldehyde. Biomol. Ther. 16, 231-236.

Lim, E. J., Kang, H. J., Jung, H. J., Song, Y. S., Lim, C. J. and Park, E. H. (2008b). Anti-angiogenic, anti-inflammatory and anti-nociceptive activities of vanillin in ICR mice. Biomol. Ther. 16, 132-136.

Olajide, O. A., Awe, S. O., Makinde, J. M., Ekhelar, A. I., Olusola, A., Morebise, O. and Okpako, D. T. (2000). Studies on the anti-inflammatory, antipyretic and analgesic properties of Alstonia boonei stem bark. J. Ethnopharmacol. 71, 179-186.

Pattekhan, H. H. and Divakar, S. (2001). Regioselectivity in the preparation of 2-hydroxy-4-methoxy benzaldehyde from resorcinol. J. Mol. Catalysis A-Chem. 169, 185-191.

Royall, J. A. and Ischiropoulos, H. (1993). Evaluation of 2',7'dichlorofluorescin and dihydrorhodamine 123 as fluorescent probes for intracellular $\mathrm{H}_{2} \mathrm{O}_{2}$ in cultured endothelial cells. Arch. Biochem. Biophys. 302, 348-355.
Sedgwick, A. D. and Lees, P. (1986). Studies of eicosanoid production in the air pouch model of synovial inflammation. Agents Actions 18, 429-438.

Sherman, M. P., Aeberhard, E. E., Wong, V. Z., Griscavage, J. M. and Ignarro, L. J. (1993). Pyrrolidine dithiocarbamate inhibits induction of nitric oxide synthase activity in rat alveolar macrophages. Biochem. Biophys. Res. Commun. 191, 1301-1308.

Singh, V. K., Mehrotra, S., Narayan, P., Pandey, C. M. and Agarwal, S. S. (2000). Modulation of autoimmune diseases by nitric oxide. Immunol. Res. 22, 1-19.

Song, Y. S., Kim, S. H., Sa, J. H., Jin, C., Lim, C. J. and Park, E. $H$. (2003). Anti-angiogenic, antioxidant and xanthine oxidase inhibition activities of the mushroom Phellinus linteus. J. Ethnopharmacol. 88, 113-116.

Tong, Y., Zhang, X., Zhao, W., Zhang, Y., Lang, J., Shi, Y., Tan W., Li, M., Zhang, Y., Tong, L., Lu, H., Lin, L. and Ding, J. (2004). Anti-angiogenic effects of Shiraiachrome A, a compound isolated from a Chinese folk medicine used to treat rheumatoid arthritis. Eur. J. Pharmacol. 494, 101-109.

Vogel, H. G. and Vogel, W. H. (1997). Drug discovery and evaluations, pharmacological assays. pp. 402-403, Springer, Berlin.

Whittle, B. A. (1964). The use of changes in capillary permeability in mice to distinguish between narcotic and nonnarcotic analgesics. Brit. J. Pharmacol. Chemother. 22, 246-253.

Yang, Y. H., Kim, Y. J. and Chung, H. Y. (2001). Peroxynitrite and hydroxyl radical scavenging activity of dihydroxybenzaldehydes. Korean J. Gerontol. 11, 24-28.

Yang, J. H. and Meng, L. C. (2008). Syntheses of 1,3-bis (2hydroxy-4-methoxyphenyl) propane and 1,3-bis (2,4-dihydroxyphenyl)propane. Chinese J. Org. Chem. 28, 918-921. 